\title{
Analyzing the Factors Associated With Nocturia in Older People in the United States
}

\author{
Joo Seop Kim ${ }^{1}$, Hye Soo Chung ${ }^{1}$, Jae Myung $\mathrm{Yu}^{1}$, Sung Tae $\mathrm{Cho}^{2}$, Shinje Moon ${ }^{1}$, Hyung Joon Yoo $^{3}$; for the Geriatric \\ Syndromes Society \\ ${ }^{1}$ Department of Internal Medicine, Hallym University Kangnam Sacred Heart Hospital, Hallym University College of Medicine, Seoul, Korea \\ ${ }^{2}$ Department of Urology, Hallym University Kangnam Sacred Heart Hospital, Hallym University College of Medicine, Seoul, Korea \\ ${ }^{3}$ Department of Internal Medicine, CM Hospital, Seoul, Korea
}

Corresponding Author:

Shinje Moon, MD

https://orcid.org/0000-0003-3298-3630

Department of Internal Medicine,

Hallym University Kangnam Sacred

Heart Hospital, Hallym University

College of Medicine, 1 Singil-ro,

Yeongdeungpo-gu, Seoul 07441,

Korea

Tel: +82-2-829-5198

Fax: +82-2-846-5198

E-mail: sinjei1128@gmail.com

Co-corresponding Author:

Hyung Joon Yoo, MD, PhD.

https://orcid.org/0000-0002-7755-9246

Department of Internal Medicine, CM

Hospital, 13, Yeongdeungpo-ro 36-

gil, Yeongdeungpo-gu, Seoul 07301,

Korea

Tel: +82-2-2678-0001

Fax: +82-2-2678-2175

E-mail: hjoonyoo@gmail.com

Received: November 12, 2018

Revised: November 20, 2018

Accepted: November 21, 2018
Background: The risk factors of nocturia in older adults remain unclear. We aimed to investigate factors associated with nocturia using the National Health and Nutrition Examination Survey (NHANES) data. Methods: Among 40,790 participants, 4,698 participants aged $\geq 65$ years were included from the NHANES dataset between 2005 and 2012. A multivariate logistic regression analysis was performed to determine the odds ratio (OR) for nocturia. A subgroup analysis was conducted based on sex and underlying diseases. Results: In the multivariate logistic regression model, obesity (OR, 1.46; 95\% confidence interval [Cl], 1.28-1.68), hypertension (OR, 1.28; 95\% Cl, 1.07-1.52), and diabetes mellitus (DM) $(\mathrm{OR}, 1.27 ; 95 \% \mathrm{Cl}, 1.11-1.45)$ were significantly associated with nocturia. These factors were associated with nocturia regardless of sex. In a subgroup of participants with hypertension, obesity (OR, 1.44; 95\% Cl, 1.25-1.67) and DM (OR, 1.26; 95\% Cl, 1.091.45) were associated with nocturia. In the additional analysis on patients with DM, nocturia was associated with obesity $(\mathrm{OR}, 1.33 ; 95 \% \mathrm{Cl}, 1.06-1.67)$ and duration of $\mathrm{DM}(\mathrm{OR}$, 1.02; $95 \% \mathrm{Cl}, 1.01-1.03)$. Conclusion: This study demonstrated that hypertension, DM, and obesity were significantly associated with the prevalence of nocturia in older adult patients regardless of sex. In particular, obesity was associated with nocturia in every subgroup analysis. (Ann Geriatr Med Res 2018;22:184-188)

Key Words: Obesity, Nocturia, Aged

\section{INTRODUCTION}

Geriatric disorders in older adults are often complex and atypical owing to multimorbidity and polypharmacy caused by several risk factors and chronic diseases. ${ }^{1-4)}$ Geriatric syndrome is defined as a condition characterized by frequent onset of disease that results in a reduced quality of life due to deterioration of different functions and response to stimulation caused by multiple factors. ${ }^{1,2)}$ Geriatric syndrome incurs disabling features in everyday life, thereby decreasing the quality of life in old age and increasing mortality in older people..$^{5)}$ Inouye et $\mathrm{al}^{2)}$ suggested the following as key disorders of geriatric syndrome: pressure ulcers, falls, functional decline, and urinary symptoms including urinary incontinence. Aside from urinary incontinence, the prevalence of other lower urinary tract symptoms (LUTS) is known to increase in older adults.

Nocturia is the most common LUTS. ${ }^{6-8)}$ According to the Korean Community Health Survey, the prevalence of nocturia has rapidly increased with aging. ${ }^{8}$ More specifically, nocturia results in reduced quality of life and work productivity in older adults. ${ }^{8-14)}$ Nocturia also increases the risk of falls and fractures by increasing the frequency of waking up to urinate during the night, which eventually results in an increased mortality rate. ${ }^{12-14)}$ Considering the increasing aging population and an environment that requires a systematic approach and therapy for geriatric syndrome, the prevalence and risk factors of nocturia in older adults should be identified.

Therefore, this study aimed to confirm the prevalence of nocturia in older adults and identify its associated risk 
factors using the National Health and Nutrition Examination Survey (NHANES) data.

\section{MATERIALS AND METHODS}

\section{Study Population}

Data were collected from the NHANES dataset between 2005 and 2012. Written informed consent was obtained from all participants, and the survey was approved by the National Center for Health Statistics' ethical review board. Participants aged $\leq 64$ years and those with missing data (urologic questionnaire, anthropometric, or laboratory data) were excluded. Finally, 4,698 of 40,790 participants were included in this study.

\section{Definition of Nocturia}

A structured questionnaire was used to investigate nocturia. Study participants were deemed to have nocturia if their answer to the following question was "two or more": "During the past 30 days, how many times per night did you most typically get up to urinate, from the time you went to bed at night until the time you woke up in the morning?"

\section{Definition of Underlying Disease}

Body mass index (BMI) was defined as weight in kilograms divided by height in meters squared $\left(\mathrm{kg} / \mathrm{m}^{2}\right)$. Obesity was defined as a BMI $\geq 30 \mathrm{~kg} / \mathrm{m}^{2}$ based on the World Health Organization criteria. ${ }^{15)}$ Hypertension was defined as having at least one of the following conditions: self-reported current use of antihypertensive agents, average systolic blood pressure (BP) $\geq 140 \mathrm{mmHg}$, or average diastolic BP $\geq 90 \mathrm{mmHg}$. Diabetes mellitus (DM) was defined as having at least one of the following conditions: self-reported current use of hypoglycemic agents or insulin, fasting plasma glucose $\geq 126 \mathrm{mg} / \mathrm{dL}$, or random glucose $\geq 200 \mathrm{mg} /$ $\mathrm{dL}$. Those with a fasting total cholesterol $\geq 240 \mathrm{mg} / \mathrm{dL}$ and those taking dyslipidemia medications were considered to have dyslipidemia.

\section{Structural Analysis}

For summary statistics, we present the mean with a 95\% confidence interval (CI) or prevalence (\%) according to the presence of nocturia. Continuous variables were assessed using a t-test, whereas categorical variables were assessed using Pearson chi-square test. Because several studies have reported that the prevalence of nocturia differs according to age, sex, obesity, and underlying diseases such as hypertension, DM, and dyslipidemia, ${ }^{8,10)}$ we performed a multivariate logistic regression analysis with these variables to determine the odds ratios (ORs) for nocturia. In addition, we conducted a subgroup analysis based on sex and underlying diseases. All analyses were performed using IBM SPSS Statistics ver. 24.0 (IBM Co., Armonk, NY, USA). A p-value of $\leq 0.05$ was considered significant.

\section{Ethical Considerations}

The protocol of NHANES was approved by the National Center for Health Statistics Research Ethics Review Board (protocol numbers 98-12, 2005-06, and 2011-17). Written informed consent was obtained from each study participant before the survey.

\section{RESULTS}

\section{Baseline Characteristics}

A total of 4,698 participants (2,375 men and 2,323 women) from the United States, aged 65-85 years (mean, 73.8 years), were examined. Among the included participants, 49.7\% exhibited nocturia (men, 51.7\%; women, 47.6\%). The anthropometric, clinical, and biochemical characteristics of the participants based on the presence of nocturia are summarized in Table 1. Compared with the participants without nocturia, those with nocturia tended to be older, male, obese, hypertensive, or diabetic.

\section{Factors Associated With Nocturia}

In the multivariate logistic regression model, obesity (OR, 1.46; 95\% CI, 1.28-1.68; Table 2), hypertension (OR, 1.28; 95\% CI, 1.07-1.52) (Table 2), and DM (OR, 1.27; 95\% CI, 1.11-1.45) (Table 2) were significantly associated with nocturia. These factors were associated with nocturia re-

Table 1. Participants' clinical characteristics obtained from the National Health and Nutrition Examination Survey dataset between 2005 and 2012

\begin{tabular}{|c|c|c|c|}
\hline Characteristic & $\begin{array}{c}\text { Normal } \\
(\mathrm{n}=2,365)\end{array}$ & $\begin{array}{l}\text { Nocturia } \\
(\mathrm{n}=2,333)\end{array}$ & $\mathrm{p}$-value \\
\hline Age (yr) & $73.3 \pm 5.6$ & $74.2 \pm 5.6$ & $<0.001$ \\
\hline Male sex & $1,148(48.5)$ & $1,227(52.6)$ & 0.006 \\
\hline \multicolumn{4}{|l|}{ Race/ethnicity } \\
\hline Mexican Hispanic & $185(7.8)$ & $270(11.6)$ & $<0.001$ \\
\hline Other Hispanics & $165(7.0)$ & $167(7.2)$ & \\
\hline Non-Hispanic White & $1,546(65.4)$ & $1,294(55.5)$ & \\
\hline Non-Hispanic Black & $378(16.0)$ & 486 (20.8) & \\
\hline Other & $91(3.8)$ & $116(5.0)$ & \\
\hline Smoking (\%) & $1,265(53.5)$ & $1,207(51.7)$ & 0.241 \\
\hline BMI $\left(\mathrm{kg} / \mathrm{m}^{2}\right)$ & $28.1 \pm 5.6$ & $29.0 \pm 6.1$ & $<0.001$ \\
\hline Obesity (BMI $\geq 30 \mathrm{~kg} / \mathrm{m}^{2}$ ) (\%) & $712(30.1)$ & $856(36.7)$ & $<0.001$ \\
\hline Systolic BP (mmHg) & $134.1 \pm 19.9$ & $135.6 \pm 21.6$ & 0.020 \\
\hline Diastolic BP (mmHg) & $65.6 \pm 13.9$ & $64.9 \pm 14.4$ & 0.114 \\
\hline Hypertension (\%) & $1,854(78.4)$ & $1,967(84.3)$ & $<0.001$ \\
\hline Fasting glucose (mg/dL) & $114.3 \pm 31.0$ & $118.2 \pm 36.9$ & 0.007 \\
\hline $\mathrm{HbA} 1_{c}(\%)$ & $6.0 \pm 0.9$ & $6.1 \pm 1.1$ & 0.001 \\
\hline Diabetes mellitus & $717(30.3)$ & $871(37.3)$ & $<0.001$ \\
\hline Triglycerides (mg/dL) & $131.6 \pm 74.6$ & $137.7 \pm 78.1$ & 0.061 \\
\hline HDL-C (mg/dL) & $54.8 \pm 16.1$ & $53.9 \pm 16.1$ & 0.046 \\
\hline Dyslipidemia & 1,615 (68.3) & $1,562(66.9)$ & 0.900 \\
\hline
\end{tabular}

Values are presented as mean \pm standard deviation or number (\%). BMI, body mass index; BP, blood pressure; DM, diabetes mellitus; $\mathrm{HbA} 1_{c}$, hemoglobin $\mathrm{A} 1_{c}$; HDL-C, high-density lipoprotein cholesterol. 
Table 2. Odds ratios for nocturia

\begin{tabular}{lccc}
\hline \multicolumn{1}{c}{ Variable } & Total & Men & Women \\
\hline Age & $1.04(1.03-1.05)$ & $1.02(1.01-1.04)$ & $1.05(1.03-1.07)$ \\
Sex, women & $0.82(0.72-0.93)$ & - & - \\
Smoking & $0.89(0.78-1.02)$ & $0.75(0.63-0.90)$ & $1.07(0.89-1.29)$ \\
Diabetes mellitus & $1.27(1.11-1.45)$ & $1.30(1.07-1.58)$ & $1.25(1.03-1.51)$ \\
Hypertension & $1.28(1.07-1.52)$ & $1.41(1.09-1.82)$ & $1.18(0.93-1.50)$ \\
Dyslipidemia & $0.93(0.81-1.07)$ & $0.89(0.73-1.09)$ & $0.96(0.78-1.17)$ \\
Obesity $\left(\mathrm{BMI} \geq 30 \mathrm{~kg} / \mathrm{m}^{2}\right)$ & $1.46(1.28-1.68)$ & $1.55(1.28-1.87)$ & $1.36(1.12-1.65)$ \\
\hline
\end{tabular}

Values are presented as odds ratio (95\% confidence interval). BMI, body mass index.

Table 3. Odds ratios for nocturia in patients with hypertension and diabetes mellitus (DM)

\begin{tabular}{lcc}
\multicolumn{1}{c}{ Variable } & Hypertension & DM \\
\hline Age & $1.03(1.02-1.05)$ & $1.01(0.99-1.04)$ \\
Sex, women & $0.82(0.72-0.95)$ & $0.84(0.66-1.06)$ \\
Smoking & $0.85(0.74-0.98)$ & $0.77(0.61-0.97)$ \\
DM & $1.26(1.09-1.45)$ & - \\
Hypertension & - & $1.23(0.83-1.84)$ \\
Dyslipidemia & $0.92(0.78-1.07)$ & $1.21(0.92-1.61)$ \\
Obesity & $1.44(1.25-1.67)$ & $1.33(1.06-1.67)$ \\
$\quad$ BMI $\left.\geq 30 \mathrm{~kg} / \mathrm{m}^{2}\right)$ & & \\
Duration of DM & - & $1.02(1.01-1.03)$ \\
HbA1 & - & $1.00(0.91-1.09)$ \\
\hline
\end{tabular}

Values are presented as odds ratio (95\% confidence interval). BMI, body mass index; $\mathrm{HbA} 1_{\mathrm{c}}$, hemoglobin $\mathrm{A} 1_{\mathrm{c}}$.

gardless of sex (Table 2). In a subgroup of participants with hypertension, obesity (OR, 1.44; 95\% CI, 1.25-1.67) (Table 3) and DM (OR, 1.26; 95\% CI, 1.09-1.45) (Table 3) were associated with nocturia. In the additional analysis on patients with DM, nocturia was associated with obesity (OR, 1.33; 95\% CI, 1.06-1.67) (Table 3) and duration of DM (OR, 1.02; 95\% CI, 1.01-1.03) (Table 3).

\section{DISCUSSION}

This study has confirmed the high prevalence of nocturia in older adults. Moreover, aside from age and sex, other factors (i.e., obesity, hypertension, and DM) were found to be associated with nocturia in a large population database.

A previous American study conducted in 2011 using the 2005-2008 NHANES data reported the prevalence of nocturia (urinating 2 or more times per night) in older men ( $\geq 75$ years old) as $55.8 \%$, similar to that in our study. The prevalence of nocturia in the younger population (aged 20-34 years) was 8.2\%, lower than that in the older adults. ${ }^{16)}$ In addition, as nocturia can result in symptoms (i.e., poor sleep, falls, and depression) that may act as risk factors of geriatric syndrome, its clinical importance should be highlighted. ${ }^{16)}$

Several previous studies have reported an association between obesity and nocturia. ${ }^{17)}$ Although the complete mechanism underlying how obesity leads to nocturia is not well known, insulin resistance and hyperinsulinemia caused by obesity can stimulate the hypothalamic center that regulates sympathetic tone. This can increase the catecholamine level, which promotes prostate growth, resulting in nocturia caused by benign prostatic hyperplasia. ${ }^{18,19)}$ In addition, pelvic atherosclerosis caused by obesity can induce deposition of ischemia-mediated altered collagen and bladder fibrosis, which induces urinary symptoms. ${ }^{20,21)}$ Although the mechanism underlying the association of obesity with nocturia is not fully understood, several studies have reported an association between weight loss and improvements in nocturia. Breyer et al. ${ }^{22)}$ reported that weight reduction improved nocturia at 6 months into a weight reduction program, compared with the obese women in the control group. In addition, another study on Korean women also reported that exercise improved nocturia in obese older women. ${ }^{23)}$ Similarly, this study has confirmed the association between the onset of nocturia and obesity-regardless of sex, DM status, or hypertension status-using large-scale data, which strongly supports previous studies demonstrating an association between obesity and nocturia. Although the prevalence of obesity and nocturia among patients with type 2 DM was higher than that among those without type $2 \mathrm{DM}$, the association between obesity and nocturia remains controversial. ${ }^{24-26)}$ Chung et al. ${ }^{24)}$ reported that BMI was positively associated with nocturia in a Taiwanese study of patients with DM. In contrast, Chiu et al. ${ }^{25)}$ showed that BMI was not associated with nocturia in another Taiwanese study of patients with DM. Furukawa et al. found a positive association between obesity and nocturia in older Japanese patients with DM but not in young and middle-aged patients. ${ }^{26)}$ A subgroup analysis in this study confirmed that obesity is significantly associated with nocturia in patients with DM.

Previous epidemiological studies assessing the association between hypertension and nocturia have demonstrated a high prevalence of nocturia in patients using hypertensive medications. ${ }^{27)}$ Hypertension can affect both glomerular filtration and tubular transport, resulting in increased urine volume. ${ }^{28,29)}$ Furthermore, medication for hypertension (i.e., calcium channel blockers and beta blockers) has also been associated with nocturia. ${ }^{28,29)}$ With reduced cardiac function due to hypertension, patients in 
the supine position at night may experience reabsorption of water from the lower limbs and circulation, resulting in an increased volume of urine and therefore nocturia. ${ }^{27)}$ Moreover, hypertension is a risk factor of obstructive sleep apnea, which results in a low oxygen level and an increased atrial natriuretic peptide level in the blood, thereby increasing the urine volume. ${ }^{29)}$ This study confirmed the significant association between hypertension and nocturia in older adults, which is consistent with the results of the previous studies.

Several previous studies have reported the association between DM and nocturia. ${ }^{27,30)}$ A prospective study has shown that DM in older adults can result in an increased urine volume at night, leading to nocturia and sleep disorder. $^{31,32)}$ Furthermore, several patients with DM have been reported to experience obstructive sleep apnea, which may have caused nocturia symptoms. ${ }^{33)}$ The present study also confirmed the association between DM and nocturia in older adults.

The significance of this study lies in the confirmation of the prevalence of nocturia and identification of its associated factors in older adults, using a large population-based dataset. Furthermore, various subgroup analyses in this study confirmed that obesity was associated with nocturia regardless of sex, DM status, or hypertension status in older adults. However, this study also has several potential limitations. First, it was a cross-sectional study. To clarify the causality between obesity and nocturia, further prospective studies are necessary. Second, because of the lack of data, most participants in NHANES were excluded from this study. Therefore, selection bias may exist.

In conclusion, this study demonstrated that hypertension, DM, and obesity were significantly associated with the prevalence of nocturia in older people regardless of sex. In particular, obesity was associated with nocturia in every subgroup analysis.

\section{CONFLICTS OF INTEREST DISCLOSURES}

The researchers claim no conflicts of interest.

\section{REFERENCES}

1. Yoo HJ. Current approach of geriatrics. J Korean Med Assoc 2014;57:736-7.

2. Inouye SK, Studenski S, Tinetti ME, Kuchel GA. Geriatric syndromes: clinical, research, and policy implications of a core geriatric concept. J Am Geriatr Soc 2007;55:780-91.

3. Kim S, Park JH, Ahn H, Lee S, Yoo HJ, Yoo J, et al. Risk factors of geriatric syndromes in Korean population. Ann Geriatr Med Res 2017;21:123-30.

4. Cesari M, Physical frailty and sarcopenia: development of a framework for supporting interventions against incident mobility disability. Ann Geriatr Med Res 2017;21:42-8.

5. Kane RL, Shamliyan T, Talley K, Pacala J. The association between geriatric syndromes and survival. J Am Geriatr Soc 2012;60:896-
904.

6. Irwin DE, Milsom I, Hunskaar S, Reilly K, Kopp Z, Herschorn S, et al. Population-based survey of urinary incontinence, overactive bladder, and other lower urinary tract symptoms in five countries: results of the EPIC study. Eur Urol 2006;50:1306-14.

7. Coyne KS, Sexton CC, Thompson CL, Milsom I, Irwin D, Kopp ZS, et al. The prevalence of lower urinary tract symptoms (LUTS) in the USA, the UK and Sweden: results from the Epidemiology of LUTS (EpiLUTS) study. BJU Int 2009;104:352-60.

8. Kim SY, Bang W, Kim MS, Park B, Kim JH, Choi HG. Analysis of the prevalence and factors associated with nocturia in adult Korean men. Sci Rep 2017;7:41714.

9. Welliver C, Sulaver R, Whittington A, Helfand BT, Cakır 00, Griffith JW, et al. Analyzing why men seek treatment for lower urinary tract symptoms and factors associated with nonimprovement. Urology 2015;86:862-7.

10. Madhu C, Coyne K, Hashim H, Chapple C, Milsom I, Kopp Z. Nocturia: risk factors and associated comorbidities; findings from the EpiLUTS study. Int J Clin Pract 2015;69:1508-16.

11. Pesonen JS, Cartwright R, Mangera A, Santti H, Griebling TL, Pryalukhin AE, et al. Incidence and remission of nocturia: a systematic review and meta-analysis. Eur Urol 2016;70:372-81.

12. Kim SY, Bang W, Kim MS, Park B, Kim JH, Choi HG. Nocturia is associated with slipping and falling. PLoS One 2017;12:e0169690.

13. Vaughan CP, Brown CJ, Goode PS, Burgio KL, Allman RM, Johnson TM 2nd. The association of nocturia with incident falls in an elderly community-dwelling cohort. Int J Clin Pract 2010;64:57783.

14. Nakagawa H, Niu K, Hozawa A, Ikeda Y, Kaiho Y, Ohmori-Matsuda $\mathrm{K}$, et al. Impact of nocturia on bone fracture and mortality in older individuals: a Japanese longitudinal cohort study. J Urol 2010;184:1413-8.

15. World Health Organization. Obesity [Internet]. Geneva (Switzerland): World Health Organization; c2018 [cited 2018 Dec 11]. Available from: https://www.who.int/topics/obesity/en/.

16. Markland AD, Vaughan CP, Johnson TM 2nd, Goode PS, Redden DT, Burgio KL. Prevalence of nocturia in United States men: results from the National Health and Nutrition Examination Survey. J Urol 2011;185:998-1002.

17. Tikkinen KA, Auvinen A, Huhtala H, Tammela TL. Nocturia and obesity: a population-based study in Finland. Am J Epidemiol 2006;163:1003-11.

18. Alvarez GE, Beske SD, Ballard TP, Davy KP. Sympathetic neural activation in visceral obesity. Circulation 2002;106:2533-6.

19. Hammarsten J, Hogstedt B. Hyperinsulinaemia as a risk factor for developing benign prostatic hyperplasia. Eur Urol 2001;39:151-8.

20. Tarcan T, Azadzoi KM, Siroky MB, Goldstein I, Krane RJ. Agerelated erectile and voiding dysfunction: the role of arterial insufficiency. Br J Urol 1998;82 Suppl 1:26-33.

21. Laven BA, Orsini N, Andersson SO, Johansson JE, Gerber GS, Wolk A. Birth weight, abdominal obesity and the risk of lower urinary tract symptoms in a population based study of Swedish men. J Urol 2008;179:1891-5.

22. Breyer BN, Creasman JM, Richter HE, Myers D, Burgio KL, Wing $\mathrm{RR}$, et al. A behavioral weight loss program and nonurinary incontinence lower urinary tract symptoms in overweight and obese 
women with urinary incontinence: a secondary data analysis of PRIDE. J Urol 2018;199:215-22.

23. Ko IG, Lim MH, Choi PB, Kim KH, Jee YS. Effect of long-term exercise on voiding functions in obese elderly women. Int Neurourol J 2013;17:130-8.

24. Chung MS, Chuang YC, Lee JJ, Lee WC, Chancellor MB, Liu RT. Prevalence and associated risk factors of nocturia and subsequent mortality in 1,301 patients with type 2 diabetes. Int Urol Nephrol 2014;46:1269-75.

25. Chiu AF, Huang MH, Wang CC, Kuo HC. Higher glycosylated hemoglobin levels increase the risk of overactive bladder syndrome in patients with type 2 diabetes mellitus. Int J Urol 2012;19:9951001.

26. Furukawa S, Sakai T, Niiya T, Miyaoka H, Miyake T, Yamamoto $\mathrm{S}$, et al. Obesity and the prevalence of nocturia in Japanese elderly patients with type 2 diabetes mellitus: The Dogo study. Geriatr Gerontol Int 2017;17:2460-5.

27. Fitzgerald MP, Litman HJ, Link CL, McKinlay JB; BACH Survey Investigators. The association of nocturia with cardiac disease, diabetes, body mass index, age and diuretic use: results from the
BACH survey. J Urol 2007;177:1385-9.

28. Selkurt EE. Effect of pulse pressure and mean arterial pressure modification on renal hemodynamics and electrolyte and water excretion. Circulation 1951;4:541-51.

29. Feldstein CA. Nocturia in arterial hypertension: a prevalent, underreported, and sometimes underestimated association. J Am Soc Hypertens 2013;7:75-84.

30. Tikkinen KA, Auvinen A, Johnson TM 2nd, Weiss JP, Keranen T, Tiitinen A, et al. A systematic evaluation of factors associated with nocturia--the population-based FINNO study. Am J Epidemiol 2009;170:361-8.

31. Shan Z, Ma H, Xie M, Yan P, Guo Y, Bao W, et al. Sleep duration and risk of type 2 diabetes: a meta-analysis of prospective studies. Diabetes Care 2015;38:529-37.

32. Nilsson PM, Roost M, Engstrom G, Hedblad B, Berglund G. Incidence of diabetes in middle-aged men is related to sleep disturbances. Diabetes Care 2004;27:2464-9.

33. Chasens ER, Umlauf MG, Pillion DJ, Wells JA. Nocturnal polyuria in type 2 diabetes: a symptom of obstructive sleep apnea. Diabetes Educ 2002;28:424-34. 